\section{Research Projects}

STUDIES IN IDENTICAL TWINS

In any counselling unit twins are likely to appear and their research value lies in the fact that they may be discordant for a particular disease. A detailed history may then suggest why this is so. Identical twins discordant for Parkinsonism, for bronchial asthma, for chronic myeloid leukaemia, and for carcinoma of the breast (where both twins had Klinefelter's syndrome) have been recently encountered in the Nuffield Unit of Medical Genetics.

\section{HYBRID CELLS}

It has long been known that some virus infections of animals and man produce lesions in which cells with two or more nuclei are frequently found, and it is now known that this is due to the ability of the virus to fuse single cells together. The virus may be used to fuse different cell types from one species of animal, or cells from different ones. The hybrid cells combine the properties of the two parents, and have, to begin with, a double set of chromosomes. The technique has been used for studying linkage (a cell lacking an enzyme being fused with a cell possessing it) and it has also recently been applied to the study of cancer. Professor Harry Harris at Oxford ${ }^{8}$ has fused highly malignant mouse tumour cells with non-malignant mouse cells, and then transplanted the hybrid cells into mice which had been irradiated to prevent them from rejecting the transplant (irradiation inactivates the immune response). Instead of a tumour forming in all the mice, which is what happens when the malignant cells alone are injected, tumours developed in only a third of them-that is, cancer did not occur as long as the hybrid cells retained the full double set of chromosomes (one whole set from each parent). When, after dividing, they gradually started to lose chromosomes, the hybrid cells began to become malignant again. Selective chromosome loss may, therefore, be a factor in causing cells to become malignant. The technique could possibly be used for assessing premalignancy, since such cells might not be so "dominant" as those from normal controls.

To conclude, as Emery says, ${ }^{2}$ medical genetics seems likely to become the preventive medicine of the future, and the subject may also be of great value from the standpoint of epidemiology.

I am grateful to Messrs Edward Arnold for allowing me to draw freely from my book Human Genetics and Medicine (1970) for part of this paper.

\section{Further Reading}

In addition to the books mentioned in the references below, the Department of Health publish a booklet called Human Genetics. A new edition will be available in 1972.

This article is based on a lecture given in the Birmingham course under the title "The Scientific Basis of Clinical Practice" (see B.M.f. 27 November 1971, p. 510).

\section{References}

1 Roberts, J. A. Fraser, An Introduction to Medical Genetics, 5th edn. London, Oxford University Press, 1970.

- Emery, A. E. H., Elements of Medical Genetics, 2nd edn., Edinburgh and London, Livingstone, 1971.

3 Clayton, Barbara E., Fournal of Medical Genetics, 1971, 8, 37.

- Auerbach, V. H., DiGeorge, A. M., and Carpenter, G. G., in Amino Acid Metabolism and Genetic Variation, ed. W. L. Nyhan, p. 11. New York, McGraw-Hill, 1967.

5 Carter, C. O. British Medical Bulletin, 1969, 25, 52. - Spock, A., Heick, H. M. C., Cress, H., and Logan, W. S., Pediatric

Research, 1967, 1, 173.
Herndon, C. N., in Methodology in Human Genetics, ed. W. J. Burdette. San Francisco, Holden-Day, 1962.

8 Harris, H., Proceedings of the Royal Society, Series B, 1971, 179, 1.

\title{
Clinical Endocrinology
}

\section{Male Infertility}

\author{
D. R. LONDON
}

\section{Assessment of the Patient}

Unwanted sterility is a problem in about $10 \%$ of the marriages in this country. In between one-third and one-half of these an abnormality can be found in the male partner. The identification of the reason for the infertility is based on both clinical assessment and laboratory investigation. Only when the type of abnormality is known can further treatment be considered.

Queen Elizabeth Hospital, Edgbaston, Birmingham

D. R. LONDON, D.M., M.R.C.P., Consultant Physician (formerly Senior Lecturer in Chemical Pathology and Medicine, St. Thomas's Hospital Medical School, London S.E.1) 
TABLE I-Clinical Aspects of Infertility

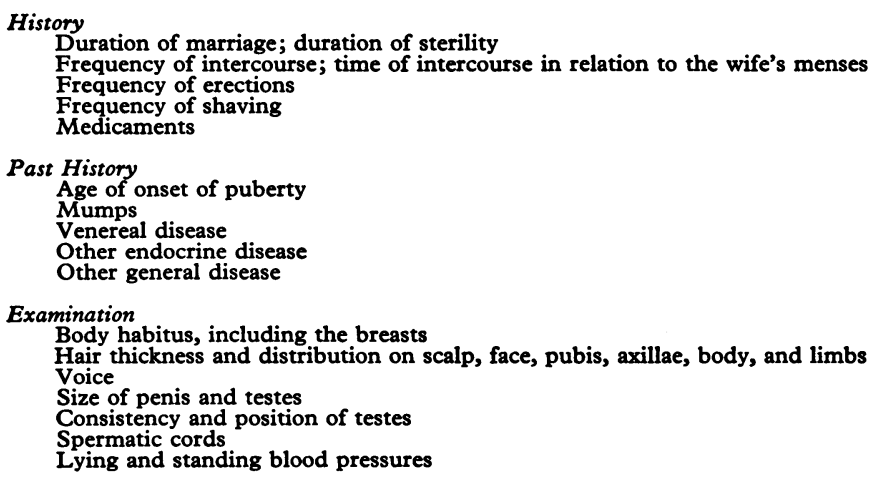

about the patient's endocrine status, as does the age of puberty. The normal boy has reached this landmark by the age of 18 . Since some drugs can cause impotence or inhibit spermatogenesis, the doctor should obtain an account of any treatment the patient is receiving. Similarly, as some illnesses can cause infertility, a past history of these should be sought after.

Though not specifically part of the study of the infertile male, the reproductive health of the wife should be assessed, as on occasions male and female infertility can coexist.

Examination of the patient may reveal abnormalities such as undescended or small soft testicles. During the examination of the scrotum the spermatic cord, particularly the left side, should be palpated with the patient standing for evidence of varicocele. Small genitalia, a high pitched voice, long limbs, and lack of "sexual" hair all provide evidence of eunuchoidism. The blood pressure should be taken with the subject both lying and standing to detect postural hypotension, and hence an autonomic neuropathy. The presence of gynaecomastia may suggest a diagnosis such as Klinefelter's syndrome.

TABLE II-Laboratory Investigations in Infertility

Semen analysis

Testicular biops

Sex chromatin

Skull $x$-ray film; radiological bone age
Measurement of plasma or urine testosterone and gonadotrophins

Culture of urine and prostatic fluid

Serological tests for venereal disease

Vasography

\section{LABORATORY INVESTIGATIONS}

The more important investigations are set out in Table II. Only a sperm count need be performed in every man suspected of sterility. The others are carried out when seeking a particular aetiology.

An abnormality in the seminal fluid serves to focus attention on the male partner of an infertile marriage. It is, however, important that the conditions under which the specimen is taken are carefully controlled, to avoid errors of interpretation. The specimen is obtained by masturbation into a clean glass tube. Before the test the patient should be told to abstain from sexual intercourse or masturbation for five days. If this instruction is disobeyed the sperm count may be spuriously low. There is, however, some controversy about what constitutes a normal sperm count. It used to be said that a total count of over 60 million constituted a normal ejaculate. However, it is now agreed that sperm concentration is more important and that 20 million or so sperms per $\mathrm{ml}$ is enough to produce fertility in most cases.

Apart from their number, the shape and motility of the sperms are also checked. When the specimen is examined under standard conditions at least $60 \%$ should have a normal form and be motile; a high percentage of abnormal spermatozoa is seen in some cases of infertility. A low seminal volume, less than $2 \mathrm{ml}$, is caused by the diminished secretion of androgens. If a hormonal disorder of the testis is suspected testosterone and gonadotrophin levels in blood or urine should be estimated. In this instance skull radiology for evidence of pituitary tumour, and radiological assessment of bone maturation should also be performed.

Since infertility may be due to abnormalities of sex differentiation, examination of the sex chromatin of the buccal squames and the chromosome pattern of white cells or fibroblasts may be diagnostically useful. Testicular histology is particularly informative in assessing these patients as it will very often point to the underlying abnormality and indicate the likely prognosis. Other tests which are occasionally of value are urine and prostatic fluid culture, serological tests for venereal disease, and vasography.

\section{Causes}

The commoner conditions causing infertility are listed in Table III. Of these, varicocele and abnormalities of the testicular tubules or interstitial cells, or both, are the disorders encountered most frequently.

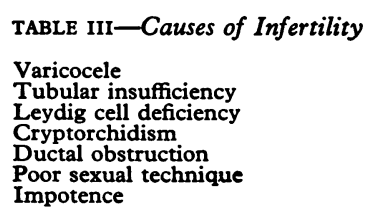

\section{VARICOCELE}

Of the various organic causes of male infertility, varicocele is the easiest to recognize and treat. It is primarily a disorder of the drainage of the left spermatic vein into the left renal vein. The condition is discovered by examination of the spermatic cords while the patient is standing. The sensation of palpating a varicocele has been described as that of "feeling a bag of worms". There is no apparent reason why this condition should be associated with a low sperm count; there is no factual basis for the much-quoted assertion that the blood perfusing the testes of a patient with varicocele is warmer than normal and therefore damaging to spermatogenesis. Nevertheless, whatever the mechanism whereby the sperm count is depressed, there is good evidence that the semen is restored to normal and fertility ensues in about half the patients treated by high ligation of the left spermatic vein.

\section{TUBULAR INSUFFICIENCY}

This abnormality is encountered in many of the males in whom there is no clinically apparent reason for a low sperm count. Patients with this disorder may appear completely normal or they may have small, soft testes. There is no evidence of androgen deficiency either on clinical examination or when testosterone levels are measured. If the disease originates in the testes the gonadotrophin measurements tend to be raised. If the testicles are affected because of pituitary gonadotrophin deficiency, concentrations of these hormones will be found to be low. A biopsy specimen of the testis shows varying degrees of immaturity of the germinal tissue. In the vast majority of cases the cause of primary tubular failure is unknown. Nevertheless, sometimes it may be due to gonorrhoea or on rare occasions follow mumps orchitis. Immunosuppressive therapy may also inhibit spermatogenesis.

\section{LEYDIG CELL DEFICIENCY}

This may result from a variety of pathological processes. These may have a genetic basis such as occurs in Klinefelter's syndrome, where there is usually a chromosome abnormality found in 
association with the other features that constitute the condition. It may also be found as a consequence of a rare developmental abnormality when there is a complete lack of testicular tissue. In all these conditions the primary abnormality is testicular involving both germinal epithelium and interstitial cells. Sometimes, however, Leydig cell atrophy is secondary to gonadotrophin deficiency consequent on pituitary disease; in this case blood and urine gonadotrophin levels will tend to be lower than normal. Histological examination of a biopsy specimen from the testis is an important adjunct in the diagnosis of this group of conditions.

Leydig cell failure will appear clinically as eunuchoidism. This can be diagnosed by the patient giving a history of shaving infrequently and having little libido. The physical findings are those of an asthenic build with disproportionately long limbs, a high-pitched voice, smooth skin with lack of the normal male hair, and small genitalia. The infertility consequent on eunuchoidism of primary testicular disease cannot be treated effectively, but gonadotrophin deficiency is more amenable to therapy. This latter condition may present as "delayed puberty".

\section{CRYPTORCHIDISM}

If both testes remain undescended by the time puberty is reached, the chances of subsequent infertility are high. Thus if the patient presents in adult life with undescended testes, the outlook for fertility is very poor indeed, and therefore this is a problem more easily prevented than cured; treatment should be undertaken in boyhood, preferably by the time the child is 7 years old. If a course of gonadotrophins fails to produce descent when there is convincing evidence of scrotally absent rather than retractile testes, orchidopexy should promptly be performed.

\section{DUCTAL OBSTRUCTION}

This should be suspected when there is an absence of spermatozoa from a normal person with relatively normal testicular histology. The commonest causes of this condition are gonorrhoea or tuberculosis, either of which may lead to blockage of the epididymis. Occasionally the vasa deferentia can be damaged at the time of earlier surgery or may be congenitally absent. The condition may be diagnosed by vasographythat is, the radiography of the vas deferens after the injection into the vas of a radio-opaque dye.

\section{POOR SEXUAL TECHNIQUE}

Problems due to ignorance or impotence may provide a basis for infertility. Too frequent intercourse or masturbation can lower the sperm count to subfertile levels. Infrequent intercourse, performed at a time when the female partner is not ovulating, is also a cause of sterility. Thus it is particularly important to inquire into the timing and frequency of intercourse.

\section{IMPOTENCE}

This can be a presenting symptom, as well as a feature discovered incidentally in the course of taking a history. Though it may be due to organic causes such as an autonomic neuropathy (which is usually diabetic), the Leriche syndrome, taking certain drugs including antihypertensives, and to endocrine disease, most commonly it is psychosexual, relating to the attitudes and habits of one or other partner. In any case of male impotence it is most important to question the female partner separately, for she may provide the clue to the basis for the complaint.

\section{MISCELLANEOUS}

It is said that a seminal volume over $4.5 \mathrm{ml}$ may be associated with infertility in some instances. The reason given is that the semen is dilute and sperms are lost when such a large volume overflows out of the vagina. If, indeed, this is a cause of sterility, it may be treated by the patient practising partial coitus interruptus with only the first portion of the ejaculate, containing the maximum sperm concentration, being deposited in the vagina.

It has also been suggested that in a few instances antibodies may be present, either in the man or the woman, which agglutinate spermatozoa. Nevertheless, the role of such a mechanism in the production of infertility has not been fully evaluated.

\section{Treatment}

Though the results of treating this group of diseases is on the whole disappointing, it is important to establish the cause of the infertility whenever possible as some conditions are more amenable to treatment than others. For example, the infertility of Klinefelter's syndrome is untreatable, but ligation of a varicocele carries a $50 \%$ success rate.

Idiopathic tubular insufficiency may be treated with gonadotrophins prepared from human menopausal urine, which is particularly rich in follicular stimulating hormone (FSH) and also contains some luteinizing hormone $(\mathrm{LH})$. This therapy is still in the experimental stage and is both expensive and timeconsuming. Since spermatozoa take about three months to mature, the injections have to be given over a long period. This therapeutic regimen is usually undertaken in a specialist unit which has the facilities for monitoring the effects of treatment with repreated sperm counts and, possibly also, occasional testicular biopsies. Some patients-more particularly those with evidence of Leydig cell failure secondary to LH deficiency -may need human chorionic gonadotrophin (which has potent LH activity) as well as the menopausal gonadotrophin preparation.

Clomiphene, a drug effective in the induction of ovulation in women, has also been used for its gonadotrophin-releasing effect in men, but to date its relative lack of success in the male is such that its general use cannot be recommended. Some satisfactory results have been obtained following the use of artificial insemination with the husband's sperm in cases of low seminal volume and sperm content.

When blockage of the larger ducts has caused aspermia, the condition may be rectified by surgical resection of the block with either vas-to-vas or vas-to-epididymis anastomosis, depending on the site of obstruction. However, when the vasa efferentia are blocked joining the vas to the testicle is not a fruitful procedure.

In cases where there is a problem with technique, simple advice and instruction may be all that is needed. Impotence of psychosexual origin is harder to treat; separate discussion with each partner may occasionally prove helpful.

\section{Further Reading}

Dubin, L., and Amelar, R. D., Fertility and Sterility, 1971, 22, 469. Jeffcoate, S. L., in Modern Trends in Endocrinology, ed. H. Gardiner-Hill and F. T. G. Prunty. London, Butterworths, 1972.

Joël, C. A., Fertility Disturbances in Men and Women. Basel, Karger, 1971. Johnson, J., Disorders of Sexual Potency in the Male. Oxford, Pergamon, 1968. Paulsen, S. A., in Textbook of Endocrinology, 4th edn., ed. R. H. Williams. Philadelphia, Saunders, 1968. 